\title{
Multisensory experience of public interiors
}

\author{
Burçak Altay \\ Interior Architecture and Environmental Design Department, Bilkent University, Ankara, Turkey
}

\begin{abstract}
We experience interiors with all of our senses, by seeing, touching, hearing and smelling as well as through our bodily interactions and orientation. Moreover, our experience is not static; it changes through moment-to-moment encounters according to changing sensations, our activities, our intentions, etc. This results in pleasant, neutral and/ or unpleasant feelings. Interior design education and practice should, therefore, include an understanding and awareness of these embodied interactions, particularly how they occur in everyday life. This study provides a multisensory perspective of everyday public interiors through the lived experiences of participants. This is accomplished through the visual and verbal reflective essays of students who mindfully observed and documented their bodily postures and sensory perceptions during different activities within a variety of public interiors, such as cafés, bookstores and retail spaces. A thematic analysis of the essays reveals not only the specific features of interiors that influence particular senses, but also how these in turn affect an individual's feelings and level of comfort. The findings point toward the temporality of experience and embodied total experience, which should be considered more focally in design education and practice.
\end{abstract}

\section{KEYWORDS}

Multisensory experience; embodied design; interior design; public spaces; mindfulness

\section{Introduction}

When we occupy a space, either as we enter it or as we dwell in it for long periods, all of our senses are influenced by our surroundings. We adapt our postures according to our intentions, we are caught by sights and sounds, we touch surfaces and we are aware of the scents that are present. Thus, we have an embodied experience. In that respect, spatial design has the possibility of not only responding to but also expanding human capacities and potential (Franck and Lepori 2007). Therefore, architecture and interior design should take into account - and can even take inspiration from - the range of activities that are performed in interiors, with a sensitivity toward the diversity of human capabilities and anthropometric data (Franck and Lepori 2007). When creating environments for people, one should take into account all components of the perceptual system, although this is rarely the case in practice. During the design process, most representations of the senses are limited (Elsen and Heylighen 2014). Particularly, the sensory cues of touching, hearing and smelling are absent. Moreover, many architects seem to only consider able-bodied users in their designs (Elsen and Heylighen 2014). Considering inclusivity, van der Linden, Dong, and Heylighen (2016) argue that the current abstract 
information formats on user needs may not fully allow the designers to incorporate them into design. Therefore, it is advisable to use information that is based on real experience and gives the designer space to make his/her own interpretations and frame the relevant findings.

Pallasmaa suggests that architects should acknowledge all the senses during their design process and asks, "How can an architect sense the sonic ambience of the design and communicate these intentions?" and "How can we articulate and specify the odors of the spaces we are designing?" $(2019,25)$. He concludes, "The seminal requirement in today's research, education and practice is to expand the designer's imaginative and empathic capacities beyond the visual realm into an embodied, empathic and immersive identification and understanding" (26). Recent research reveals that the senses function relationally rather than one sensory modality at a time; as such, at any moment many parts of the brain (which was once believed to be modality-specific) are currently involved in multisensory processing (Howes 2006). This has strong implications for the experience of architecture. The atmospheric sense in a space is achieved not through senses working independently, but experienced in totality as a person is immersed in it and interacts with it through the relationships of the senses (Pallasmaa 2005, 2015, 2019). Moreover, sensory hierarchies (i.e. how one prioritizes one sense over another) within a space may be influenced by many factors, ranging from the needs for the task at hand, the expectancies from certain spatial functions or the social and cultural context of the person (Nanda 2005). Nanda $(2005,2017)$ calls for a "sensthetic approach" to design, in which designers pay attention to how different sensory modalities correspond to each other according to the specific requirements of a setting (such as a recreational or healthcare setting). With a sensitivity toward sensory hierarchies and expectations, a coherence among the sensory stimuli within a space can be achieved. As such, different sensory cues can transform how people experience a space. For example, the introduction of a pleasant fragrance into a room may have a positive impact on a person's mood, whereas the soundscape of an environment may deeply impact their feeling of restfulness or, conversely, overload. Malnar and Vodvarka (2004) suggest approaching and designing a space as a construct formed and experienced by our senses that includes the passive touch of air/temperature/humidity via the skin, basic orienting and kinesthesia (the position and movement of body parts), in addition to the senses of vision, hearing and smelling.

Scholars have pointed to successful examples in which all the senses are equally evoked and appreciated within architectural spaces (Franck and Lepori 2007; Malnar and Vodvarka 2004; Murray 2007; Pallasmaa 2005). Zumthor suggests that the sensuousness of architecture, primarily due to its materiality, is the point from which all design emerges (1998). Moreover, when designing furniture for interiors, designers should not only consider "ergonomic" principles (which view the body in physical and anatomical terms rather than sensuously interacting with the immediate environment) but also "somatic" principles (which view the mind-body system as an interdependent whole and account for the cultural, psychological and emotional aspects in direct relation with the physical system) (Cranz 1998).

In order to be able to design environments that embrace the body and the senses, designers should first be aware of their own embodied relationship to space. This can support user-centered design, where they utilize their own subjective experience through 
"introspection" (Xue and Desmet 2019). This way, experience-driven design knowledge can emerge and inform the design process.

This paper explores the space-person relationship from an embodied perspective within public interiors. The main goal is to explore how public interiors in everyday life are experienced through multisensory and bodily awareness. Accordingly, the following research questions are posed:

- What are the properties of public spaces, as sensed from an embodied perspective?

- How do these properties influence the participants' experiences (mainly their feelings and level of comfort)?

These research questions are explored through case studies of the application of multisensory accounts of interiors as experienced by interior design students.

\section{Materials and methods}

In the Department of Interior Architecture and Environmental Design of Bilkent University in Ankara, Turkey, "Human Factors/Ergonomics" is a single semester course. Within this course and in other educational settings, empathic and inclusive design methods have been adopted over the years (Altay 2014, 2017). During the semester, students are exposed to the principles of ergonomics and anthropometry with a focus on the usercentered design of interiors, particularly concerning the activity requirements of people with diverse abilities and physical capabilities. Within this context, a single semester case study assignment was given to the students in order to increase their sensitivity to the multisensory and bodily experience of interiors.

For the assignment, in addition to the repertoire of design education methodologies, a key source of inspiration was the set of instructions and strategies proposed in the literature on mindfulness. Varela, Thompson and Rosch refer to mindfulness/awareness practice as a way to examine the present moment experience and observe the mind (1991). Sucitto defines mindfulness as "staying with what you're doing in an attentive way, bearing it in mind" $(2015,9)$. In an overview of many definitions, Khoury et al. suggest that all conceptualizations imply an embodied perspective, where "mindfulness increases awareness of the complex interaction of the body states with cognitive and emotional processes" (2017, 1167).

There are a range of mindfulness practices to encourage nonjudgmental awareness within the present moment. Within these, "the four contemplations of mindfulness" stand out since they, according to many scholars, form the basis of all mindfulness practices. As Thera explains: "They extend from the body and its functions to the feelings as well as to the processes and contents of perception and thought" $(1988,57)$. These instructions can be carried out either through formal practice in a specific posture (i.e. sitting, standing, etc. for a specific duration) or immersion in the moment-to-moment everyday experience of the practitioner.

For this study, the two contemplations of body and feeling is attended to. Instructions for the contemplation of the body include mindfulness of the body's postures (Nhat Hanh 1987; Thera 1988). When contemplating on the postures of the body (sitting, standing, lying down), one knows that there is a body and that the posture is carried out. One may 

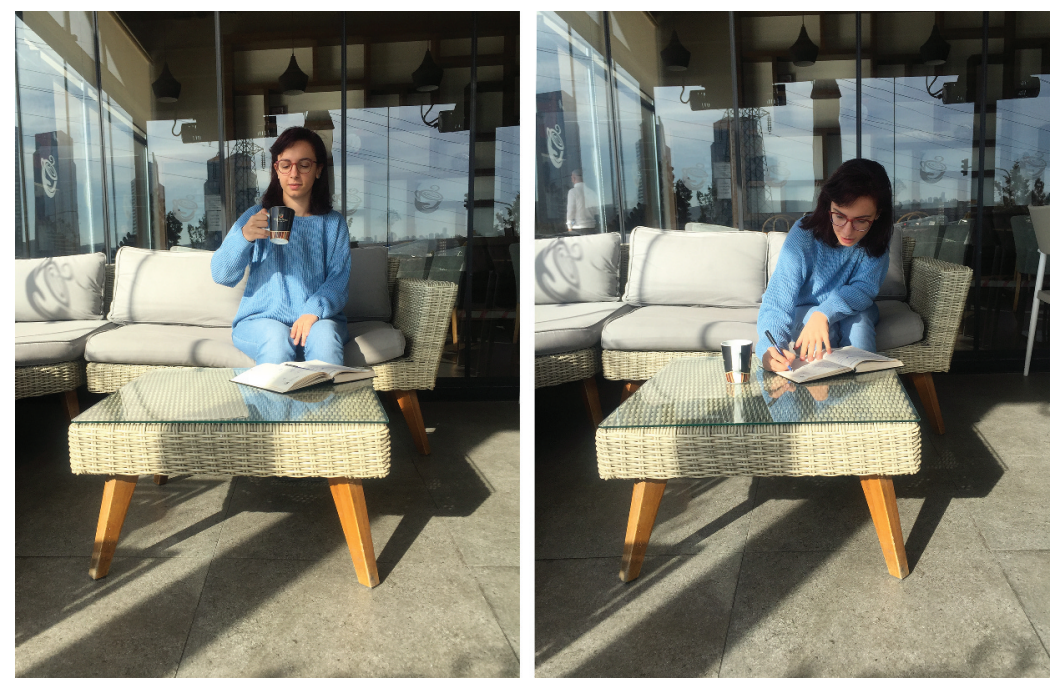

Figure 1. Two activities carried out in the same space (image credit: Serra Koz).

also choose to focus on one sense perception, such as sound, touch, etc., or observe them all as they arise and pass. As regards the contemplation of feelings, one acknowledges his/ her feelings as pleasant, neutral and unpleasant. S/he may either focus on one of these qualities within the present moment experience, or nonjudgmentally observe all of them as they wax and wane in the mind.

For this study, the students acted as participant observers as they experienced public interiors with guidance from the assignment. They analyzed their activities within interiors by focusing on their body and senses. After choosing a public space (i.e. restaurant, bookstore, shop, hair salon, etc.), they carried out two tasks. The first was to choose one subspace and conduct two different activities within that same space. For example, one could study or eat and drink within a single table-seat setting (Figure 1). The second was to carry out the same activity in two different subspaces. For example, one could choose to read a book from either a bookcase with shelves or a display counter, which required different postures (Figure 2).

All activities were enacted with a minimum duration of 5-10 minutes. The sequence of activities were documented. During these activities, the students were asked to:

- Identify all the bodily-sensory encounters that they experienced throughout the duration of the activities.

- Identify all the bodily-sensory inputs they received from the artifacts/environment that were occurring unintentionally and momentarily and that impacted the experience.

- Identify whether each experience was pleasant, unpleasant or neutral.

This way, students could investigate the sensory and bodily interactions with the spaces as well as the emotional effect.

Following the required task, each student produced reflective essays documenting their experience in the form of a "case report." The report contained written material, ranging between $200-800$ words and plan sketches of the spaces as well as photos. This 

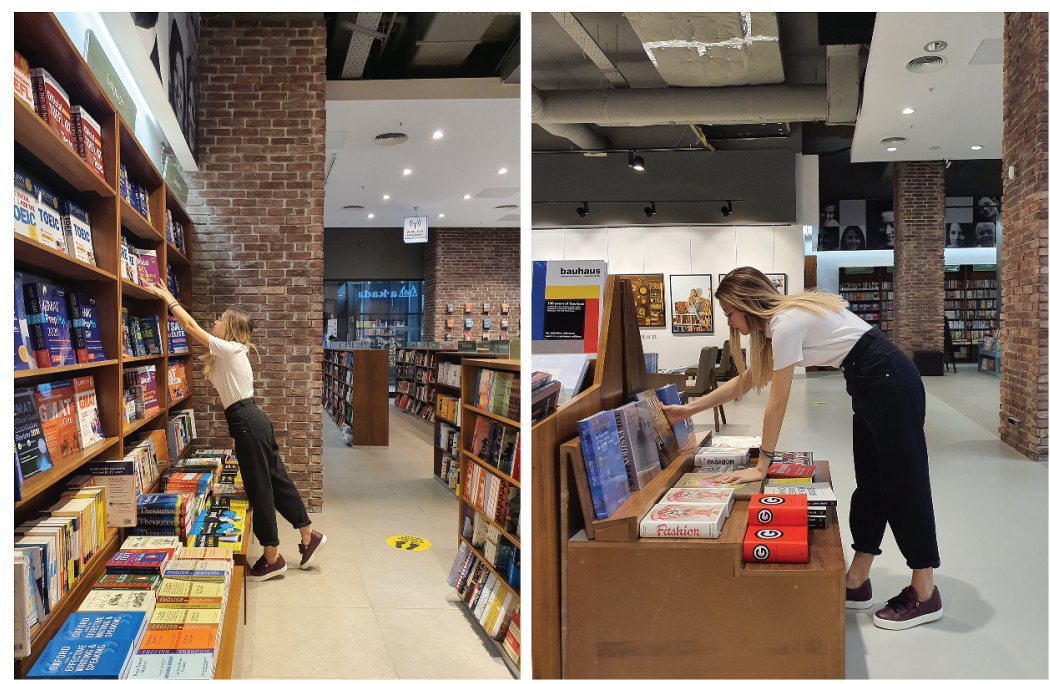

Figure 2. One activity carried out in two different spaces (image credit: Müge Sarıgöl).

way, they were involved in the different stages of the task with full participation, using a variety of representation methods (Pink 2012).

During the semester, a total of 49 students submitted reports. Forty-six of these reports were considered eligible for analysis. According to the study's objectives, the instructor/ researcher analyzed students' reports by the qualitative approach of thematic analysis (Boyatzis 1998; Braun and Clarke 2006). This process was used for identifying the themes, which gave insight into the sensory experiences of the students based on their reflections.

A thorough analysis by the researcher resulted in eight main themes (or categories). The analysis started out with extracting the data and coding them around the subjects, which in this case, started out with the sensory domains. Thus, the first five main themes ("touching/postural criteria," "sights," "sounds," "smells," and "temperature") were located in rows; all the interior design features corresponding to each theme were coded ("existing" - "1" or "not existing" - "null") for every respondent in the columns. These were continuously renewed with each respondent's data. Following these five themes, the data revealed three domains of a multisensory nature rather than fitting into a single sensory quality. These formed the final three themes, "location/orientation in space," "temporality of experience" and "the total experience." Each main theme also includes emerging subthemes that covers and summarize the related content. The resulting Table 2 in the following section represents an overview of all the sensory features of the interiors as described by the participants. In addition to this, findings also reveal the "affective dimension" (i.e. how dimensions of these features influence a positive, neutral or negative feeling; comfort or discomfort; etc), as the following section highlights.

\section{Results}

Of the 46 students that submitted essays, 32 (70\%) of them were female and $14(30 \%)$ were male. Overall, 42 different public spaces were observed. Of these, 26 (62\%) were 
Table 1. Postures and activities adopted in public interiors by 46 participants.

\begin{tabular}{|c|c|c|c|}
\hline & Theme: Postures & Sub-themes: Related Activities & No. of Participants \\
\hline \multirow[t]{8}{*}{1} & Sitting & Eating and Drinking (dining)/drinking only & (29/ 12) 41 \\
\hline & (total 108 & Reading a book & 28 \\
\hline & activities) & Studying - with pen and paper/ laptop & $(19 / 5) 24$ \\
\hline & & Chatting with friends only & 6 \\
\hline & & Carrying out a phone conv./listening to music on mobile & 2 \\
\hline & & Getting hair cut & 3 \\
\hline & & Playing cards, watching TV & 2 \\
\hline & & Receiving make up & 2 \\
\hline \multirow[t]{6}{*}{2} & Standing & Getting an artifact from shelf /display or coffee counter & 23 \\
\hline & (total 48 & Paying cashier at cash desk & 9 \\
\hline & activities) & Choosing eatery from display & 8 \\
\hline & & Reading a book & 6 \\
\hline & & Searching for a book in computer catalog & 1 \\
\hline & & Trying out shoes in shoe store & 1 \\
\hline
\end{tabular}

cafés, coffee shops, pastry shops, restaurants, etc. This was followed by eight (19\%) bookstores/libraries and five (12\%) retail/markets other than bookstores (clothes/ shoe/ cosmetic shops and supermarkets). Finally, three (7\%) female students visited hairdressers.

Since each student carried out the same activity in different subspaces and also carried out different activities within one subspace, they had a chance to investigate a variety of postures and activities. Table 1 (above) presents the main postures adopted in the public spaces and the related activities.

Table 2 (below) represents the main themes and subthemes that show all the participant experiences that emerged from the data. The main purpose of this study is to offer the diversity and range of sensory attributes of public spaces from the participants' perspectives, rather than to generalize the findings. Therefore, the prevalence of each encountered attribute has not been shown in the table.

\section{Experiencing space through bodily postures}

The two main postures that participants adopted were the sitting and standing posture. They would sit in cafés/restaurants or designated spaces in bookstores. While sitting, they could eat and drink, study and read, chat with friends, listen to music or a combination of these.

The activities carried out while sitting required a direct contact with the seat and often, the table. Therefore, the design parameters of the seat and the relation of the seat and table were major sources of comfort and/or discomfort for the users. Since the analysis assignment was part of the Human Factors course, the students gave a lot of attention to distinguishing all of the design parameters of seats that influenced their experience. Following ergonomic standards (Pheasant 2000), they evaluated seat height, seat depth, backrest height, location and contour, seat width, backrest angle, armrest height, seat material and softness.

The majority of users had a positive feeling if the seating units had armrests and ergonomically appropriate backrests (neither too high nor too low and a spacing for the buttocks) and if the upholstery allowed a natural posture. In that respect, the surface material and the softness of the seat shaped the comfort level. Meanwhile, surfaces that were too 
Table 2. Themes regarding the bodily and sensory experience of public interiors.

\begin{tabular}{|c|c|c|}
\hline & Main theme: Body/Senses & Sub-themes: Content/objects of contact \\
\hline \multirow[t]{4}{*}{1} & Touching + & Seat and table parameters \\
\hline & Postural & Cashier counter parameters \\
\hline & Criteria & Shelving and display parameters \\
\hline & & Flooring Parameters \\
\hline \multirow[t]{9}{*}{2} & Sights & Color scheme of space \\
\hline & & Light (natural, artificial, task lighting) \\
\hline & & Views (interiors and toward exterior) \\
\hline & & People (other customers, personnel, friends) \\
\hline & & Equipment (coffee/cashier machine, air conditioning system etc) \\
\hline & & Sold artifacts (products, food, menu etc.) \\
\hline & & Other furniture (types of seats, counter, etc) \\
\hline & & Service areas (kitchen, wc etc.) \\
\hline & & Being seen by others \\
\hline \multirow[t]{5}{*}{3} & Sounds & Music/TV \\
\hline & & People (other customers, personnel, friends) \\
\hline & & Equipment (coffee/cashier machine, air conditioning system, tableware sounds) \\
\hline & & Announcements of sold products \\
\hline & & Silence/quietude \\
\hline \multirow[t]{4}{*}{4} & Smells & Food and drinks (pastry, coffee etc.) \\
\hline & & Books and paper \\
\hline & & Smoke/ wc or sewage smell/ detergent \\
\hline & & Flowers \\
\hline \multirow[t]{2}{*}{5} & Temperature & Constant temperature of space (hot/warm/ideal/cold) \\
\hline & & Changing temperature of space (cold from exterior door, heat from hair dryer) \\
\hline \multirow[t]{3}{*}{6} & Location/ & Distance to/orientation toward circulation, passageways and int. /ext. \\
\hline & Orientation in & Distance to/orientation toward other chairs/tables \\
\hline & Space & Distance to/orientation toward services \\
\hline \multirow[t]{3}{*}{7} & Temporality of & Activity change of the participant \\
\hline & Experience & Changing sensitivity level of the participant \\
\hline & & Change in external stimuli \\
\hline 8 & The total experience & \\
\hline
\end{tabular}

hard (e.g. wood, metal) or too soft (leading to sinking) and slippery material (such as artificial leather) were sources of negative affect. In a table-seat setting, users also observed the impact of thigh clearance, knee space, table height, table size and material (Figure 1).

The same seat-table unit could have either a pleasant or an unpleasant effect on a user depending on the type of activity. Thus, the postural requirements for one activity (e.g. drinking coffee) varied from another (studying with pen and paper). For example, while conversing with friends around a table did not result in discomfort, when a participant studied on the same table, it was inadequate in size and surface irregularities caused trouble when writing.

In standing posture, users could reach for a book from a shelf, choose a pastry from a display stand, buy goods in a supermarket or pay a cashier behind a counter (Figure 2). In these cases, one's immediate relationship with furniture often influenced comfort levels. Users did not have a problem when the attended object was in an ideal position - eye level or elbow level. However, when it was below or above this level, it created the problem of reaching and bending. This happened occasionally at the bookstores regarding higher and lower shelves, as expressed by one participant that empathized with other diverse users:

The problem is that some of the bookshelves are extremely high for a short person to reach the books on the top. A tall person on the other hand, has to bend to reach the books at the lowest point. This is also problematic for old people who have back ache and aching joints. 
The most important postural constraint at the cashier desk was the distance between the cashier and the user. Some cashpoints had inaccessible spaces for users' belongings and this created discomfort; others had more space and resulted in a feeling of comfort. When the counter was also used for display purposes, this caused participants to be in close physical proximity with other customers, or caused them to drop products. They were aware of the conflicting activities at the cashier desk which required consideration from interior designers.

\section{Experiencing space through sights}

In their essays, rather than the general impression of a space, students were mainly attentive to the sights that had an impact on their activities. In that respect, the majority were aware of the nature and quality of light within space. While natural light, either from skylights or windows, was always appreciated, the quality of artificial lighting was also significant. It could be too bright, ideal, or too dark according to their preference and activity type. Whether the lighting quality supported the color scheme of the interiors also resulted in either a pleasing or disturbing atmosphere. Related positive design qualities were high ceilings and spaciousness, which was also at times supported by exterior views. Thus, participants choice of seating in cafés largely depended on natural light and exterior view (Figure 3).

Besides the interior design qualities, the most mentioned "sights" related to people. While users were happy about being close to friends, they had different feelings when they saw other customers, particularly influenced by how close they were and the level of privacy they preferred. Accordingly, not only seeing people but also being seen by people could cause concern.

Seeing products/artifacts was important, depending on postural requirements of the specific activity (as discussed with the previous theme). Participants preferred to observe goods that were at or below eye level, whether in a retail store, pastry shop or book store. In contrast, difficulties arose when they could not see what they intended to.

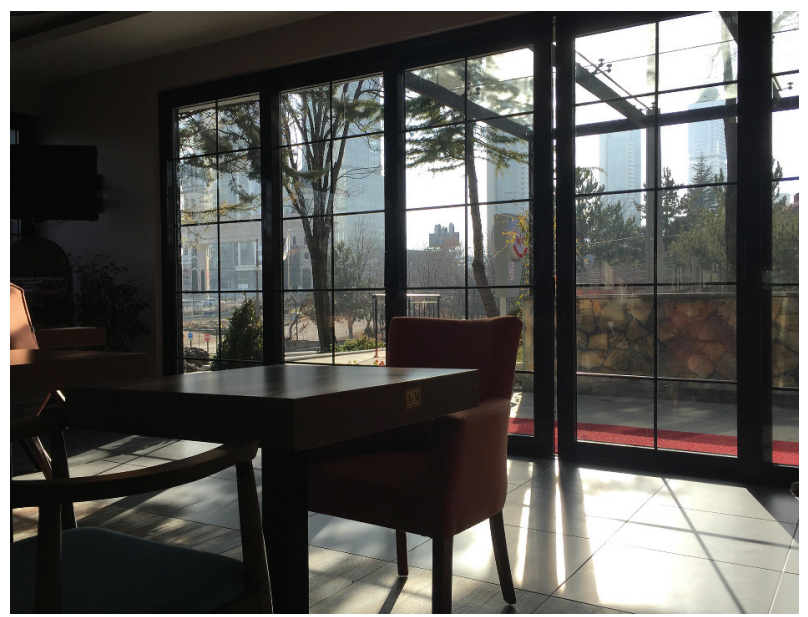

Figure 3. Exterior view and natural light as pleasant (image credit: Serra Koz). 
The visual impression of a setting and its furniture at times gave direction to the choices as to how participants would behave in the setting. In cafes, their choices depended on the orientation of the seating arrangement within space as well as assumptions about its comfort based on the view. Sometimes, visual impressions did not match their bodily comfort, as one user experienced:

After I chose the book that I wanted to read deeply, I was looking for a place to sit, then I saw the large seating. The seating was green fabric, it was soft and big. It was initially really comfortable but after five minutes I wanted to put my arms somewhere and it did not have armrests, so I started moving to find the right position for my arms. Then my neck started hurting and I realized the backrest of the seat is too low for me.

This comment also points out the temporally changing quality of experience, which we will discuss further.

\section{Experiencing space through sounds}

Participants were highly aware of and influenced by music in the spaces; the music type and sound level were important. It either added to the atmospheric quality or distracted users from their activities, such as studying or chatting with friends. Additionally, the sound of people was very influential. In this respect, users identified who was speaking, how close they were and whether it led to an agreeable or disagreeable condition.

Pleasant sounds were those of conversations with friends, particularly if the background sound level did not prevent it. Participants reported that cashier-seller conversations, shouts from staff, customer chatter and crying children were distracting and disagreeable. Similarly, sounds from machines (coffee machines, air conditioning equipment, cashier machines, etc.) and tableware created noise that users were unpleasantly aware of:

There were the sound of dishes which distracted my attention. Additionally my nephew who is 16 months old made too much noise and we could not keep him quiet which was an irritant for other customers. However, after a while, the sound of dishes disturbed me so much that my nephew's little crazy noise was not as bad as that.

In the hair salons, all three users complained about the noise of hair-dryers as they affected their well-being and gave them headaches.

In that respect, a "lack of sound" (i.e. quietude) was an appreciated quality of space, particularly when supported by sitting alone and resting, reading a book or studying. For many, it was a determinant in space selection and duration of stay. Users could achieve this quietude on their own; in one case, a user chose to put on earphones and listen to music when she was disturbed by external noise.

\section{Experiencing space through smells}

Across public interiors, participants became aware of the changing smells that widely influenced their experience. They commented on the nature, type and intensity of the smells as these led to positive or negative feelings. For example, scents coming from the immediate surroundings, such as that of flowers, were a source of happiness (also enhanced by their visual qualities) (Figure 4). 


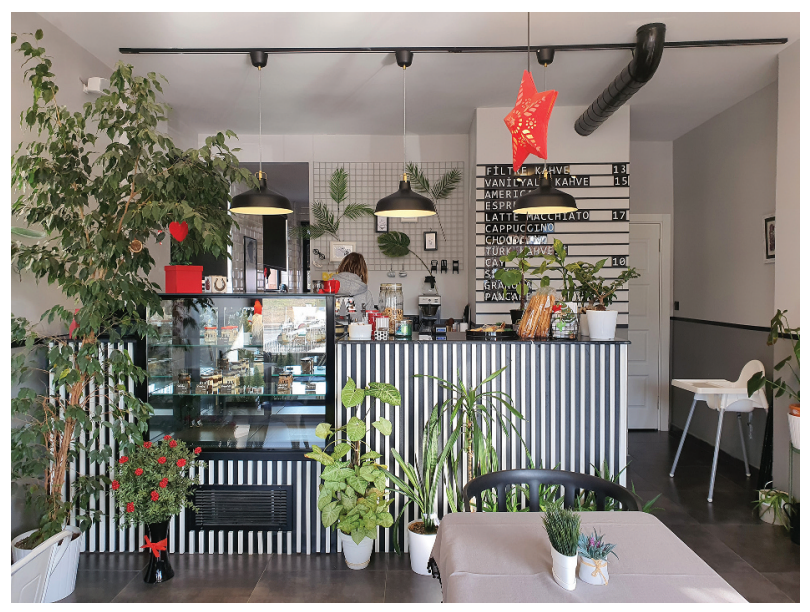

Figure 4. Smell of pastry and flowers as pleasant (image credit: Müge Sarıgöl).

With a majority of the cafés and restaurants subject to analysis, food was a major source of smell. Many expressed that the smell of food made them hungry and encouraged them to buy food and drinks. However, the smell was not always pleasant:

There was a mixture of the smell of meat coming from the restaurant part and the smell of coffee, tea and cake coming from the cafe part. So, because of this adjacency, people in the cafe were troubled with occurring smells.

Another smell that was mentioned was that of sewage/toilets, either coming from inside (due to proximity to toilets) or outside. Moreover, detergents created scent when the user was in certain areas of a supermarket; another user encountered cleaning equipment in a café. Finally, users also smelled smoke coming through smoking-designated areas and hair dye in hair salons, both unpleasant experiences.

\section{Experiencing space through felt temperature}

The majority of users were satisfied with the temperature of the interiors, which they felt were ideal. However, there were some spaces which were too hot and stuffy - the hairdressers and some retail stores and cafés. Particularly in hair salons, participants found that the fluxuating temperature of water on their heads, either too hot or too cold, did not comply with their expectations.

The warmth of a space was sometimes sensed as pleasant, especially when individuals were coming from outside. On rare occasions users reported unpleasantly cold interiors when air conditioning and heating systems did not work properly. Several users were affected by the change in temperature when they stood in front of the door at cashierpoint or sat at a table close to the door. This always resulted in the unexpected and unintentional immersion to cool air coming from the door via circulation and from which users felt dis-ease. The following comment explains this and points to the orientation of the seat within the larger space (our next theme): 
Because I was sitting near the automatic door, whenever it opened, I was cold and people who got inside interrupted me somehow, and because I was sitting in front of the cashier, everybody was able to watch me and it was disturbing.

\section{Experiencing the orientation and location within the larger space}

While the sense bases and bodily postures were clear in terms of observation, a very important aspect within space affected many participants' feelings and therefore requires a theme title: the location within larger space. This relates to the distance and orientation toward the participants' location to the main circulation path, other tables/chairs, services such as kitchen and toilets, exterior view and retail products. The orientation in turn influenced other sensory modalities, such as posture, hearing and seeing. The following comment illustrates the strong interdependency of sight and orientation:

When sitting at the table, if you are sitting towards the counter you unintentionally watch what the waiter is doing. If you are sitting towards the opposite side, you watch who comes to and goes out of the cafe. Seeing these can be a distraction, but does not have a certain positive or negative effect. Also, if you are facing the counter you can see the food coming. If you are facing the other way, you can see the outside world but cannot see the food coming.

Users reported an experience as largely unpleasant when the location did not support the activity. This was particularly the case for people waiting in a queue to pay, glancing at a book in front of a shelf or buying products in a retail store or supermarket. In such cases, they had to make adjustments - sometimes with no success - in order not to block passage (Figure 5).

While participants reported their experiential accounts in accordance with their activity/space units, they were also able to observe the sequential dimension of their interaction within the space, either within the duration of one activity or between each activity. Rather than seeing events as occurring separately in frozen timeframes, the changing nature of their experience emerged as a theme.

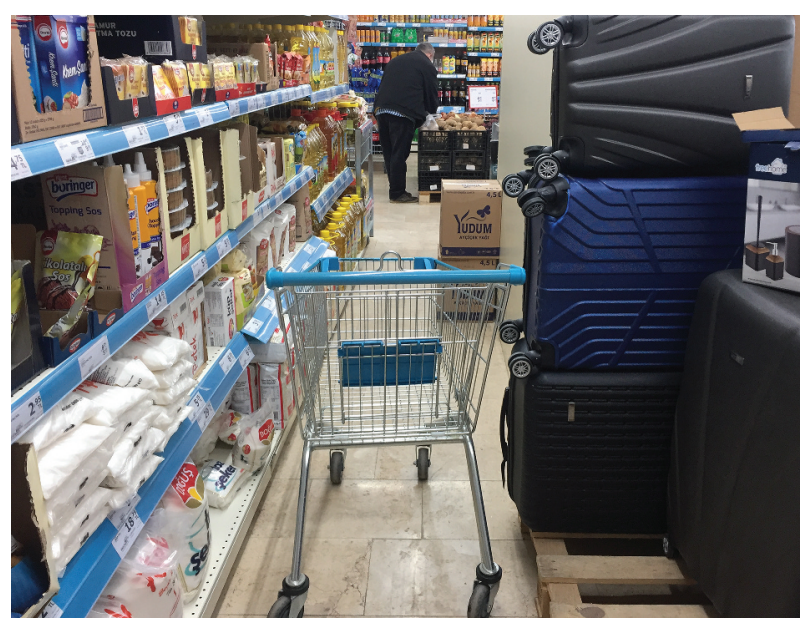

Figure 5. Activity blocking circulation as unpleasant (image credit: Serra Koz). 


\section{Temporality of experience}

The essays revealed temporal features of an activity within a setting in three different ways.These impacted the changing quality of experience and influenced participant's satisfaction levels.

The first influential feature was activity change of the participant, explored above. Thus, the features of a subspace may allow comfort in one activity and cause discomfort in another, resulting in different preferences. Particularly in the seated posture, this was obvious in repeated cases. For example, participants could drink coffee and chat with friends easily seated at a low table; however, when they studied at the same table they had to bend over, which led to discomfort. Similarly, although retrieving a book from a shelf would not cause a problem, reading a book just in front of it with people passing behind could cause a disturbance.

A second feature that influenced experience quality was the changing sensitivity level of the participant. Usually, without change in the external stimuli, one would receive the same stimuli without a major experiential shift. More often though, continuous exposure to the same stimuli caused discomfort after a prolonged period. The participant who felt bodily discomfort after sitting in a seat for a long period is such an example. Another is a user in a coffee shop seated near the coffee machine who expressed discontent after a while when the sound of the machine started annoying her. Likewise, one user noted that the continuous smell of sewage started to make her feel sick; another participant felt sick due to a lack of air and constant heat within the interiors. Here we observe how levels of tolerance change during the length of stay in one space. A shift in attention and focus of a user may also influence their views. As such, a participant noticed the circulation around the toilets after sometime, and felt discomfort from that point forward.

The third apparent feature was the change in external stimuli. This change could be contacted through all senses: sights, sounds, touching and smells. For example, the number of people nearby, perceived through sight and sound, could have a negative impact increasing sensed crowding, or positive impact increasing sensed privacy:

It was very noisy and crowded at first during lunch time. We could not even hear each other's voices. Afterwards though, it became quiet and [more] pleasant, so we prolonged our stay and were able to concentrate on our study.

Particularly when a pleasant experience turned into an unpleasant one, participants took action. One was, obviously, to leave the space. Another was adaptation, such as putting on earphones, changing postures, etc. These point to the many sub-activities performed by people in support of the main activity. Additionally, while participants distinguished and singularly identified sensory modes within a time frame, many of them expressed their lived experience stressing the multisensory mode. This leads us to the final theme: the total experience.

\section{The total experience - toward a multisensory embodied presence}

While the participants were mostly able to identify and isolate their sense contacts and influence on their feeling, the overall impression and feeling quality one had within a dedicated time frame rarely depended on a single sense contact. Many participants 
described their experience in terms of how one sense-contact related to and connected with another, resulting in the overall impression. The sensory input while ordering food from the counter is observed below:

The sensory requirements were: seeing the coffee list, food; touching and taking the juice, touching the counter surface, hearing the music, seeing and talking to the barista; and smelling the coffee (...) While the height of the food racks was pleasant, the height and distance of the coffee menu (on the back wall) was unpleasant. (emphasis added)

In this example, the participant, in a limited duration of ordering coffee, pays careful attention to the spatial and bodily awareness, detecting all sensory input from the external conditions. She concludes with how the height of the food rack and the distance of the menu affect her posture and sight capability, resulting in a variety of feelings.

In many conditions, feelings of "calm," "relaxing," "disturbing," and "annoying" resulted from a multitude of sights, sounds and bodily comfort, often interacting with each other. The following example illustrates:

The music was really complementing the theme of the cafe and the cold weather outside that only encouraged us to get hot drinks to create a perfect scene. We would gaze outside every once in a while through the glazing or try to peek at the higher platform. The transparent glazing kept us connected with what is happening outside the 'cottage-like' cafe. (emphasis added)

Here, looking through wooden glazing from within the café gave a warm impression and, combined with the taste and smell of coffee and sound of the music, lead to a sense of joy. All of the senses were at work in this perception.

\section{Conclusion}

This study explores and provides a bodily and multisensory inventory of public interior spaces in Ankara as experienced by young adult participants as a part of their Human Factors course. In this study, the participant's own experience "in place" and "in practice" (Pink 2012) is the main focus. In order to reveal the moment-to-moment direct experience, participants carry out activities in public spaces based on instructions that were adapted from mindfulness literature (Nhat Hanh 1987; Sucitto 2015; Thera 1988). These instructions encourage participants to observe their momentary bodily and sensory impressions as well as their feelings in everyday interiors. The findings of the study are based on their reflective essays about their experiences.

The findings yield insights into the nature and content of their experience through sights, sounds, smells, touch and orientation in spaces ranging from cafés, bookstores, retail spaces, etc. The participants noted their positive, neutral and negative feelings in (mostly) sitting and standing postures as they ate and drank, read a book, paid for their goods and socialized with friends.

The multisensory processing (Howes 2006) is pronounced in the findings as participants engaged with their surroundings. Moreover, their affective relationship with the environment changed over time. This supports Pink's proposition that people do not experience a space in a static way but within a constantly changing multisensory field which is dynamic and known through movement (2012). Thus, rather than a conceptualized and generalized overview of a study of interiors, this study proposes 
a person-centered, situation-based, temporally conditioned investigation of spatial experience residing in everyday mindful awareness. As suggested by other researchers (Cranz 1998; Malnar and Vodvarka 2004; Pink 2012), a practice-based holistic approach reveals the interdependency of specific design features on the sensory perceptions, activities, and feelings of people. The totality of experience supports the "sensthetic" approach proposed by Nanda $(2005,2017)$, where the interdependency of different sensory modalities within a space are identified.

Researchers have been interested in the experiences of the urban environment that engage our senses, providing a rich analysis of encounters (Imai 2008; Irving 2013). Similarly, significant buildings, which enrich our sensory presence, have been studied (Murray 2007; Temple 2006). This study complements such research and widens the investigation to include everyday public interiors. It explores the sensory perceptions that emerge through participants' lived experience in spaces, with a specific focus on activities. Thus, it accounts for the setbacks and potential of interiors within moment-tomoment changing everyday practices. From the comfort level of the body while sitting on a chair to standing in front of a counter, from the view of exteriors to the sound of people and music, from the smell of coffee to the temperature of the space, findings invite designers to take into account the complex and multisensory spatial experience during their design process. Findings also reveal the common and unique features of space types and how they impact experience.

This study has certain limitations mainly regarding the variety of interior spaces and diversity of participants. The type of spaces and the duration they are encountered have a limited scope. Therefore, the repertoire of interior spaces need to be expanded, ranging from residential settings to educational or office spaces. A deep investigation of activity-sense relationship in longer durations can be conducted. Moreover, the findings of the study point to both common and unique experiences of the participants who are of a similar demographic background within a specified context. Complementing this research to include the views and experiences of people with disabilities, children, the elderly, is essential. For this, empathic methods such as simulation, roleplaying, interviewing, observation, etc. (Altay 2014, 2017) and other visual methods, such as photo-essays, videos etc. (Pink 2012) can be utilized. In any case, mindfulness instructions can be expanded and used within a variety of similar contexts since the instructions increase attentiveness to the present moment and, therefore, enhance spatial and multisensory awareness. Further applications within this terrain are open to exploration.

The findings of this study call for sensitivity in the design of every spaces that accommodates the bodily postures, sights, sounds and smells that each activity requires. With the changing status of public interior spaces since the pandemic outbreak, this study raises even more questions for exploration. How can our public spaces encourage a multisensory embodied presence while preserving the social richness, health and safety of all participants? What are the parameters of spaces that can enhance the comfort and positive feelings of users, thereby adding value to our lives? As designers, we must cultivate multisensory awareness to reflect to our education and practice if we want to design places that include everyone and support, equally, their human potentials. 


\section{Acknowledgments}

I would like to thank David Howes and two anonymous reviewers for their support and constructive comments. I would also like to thank all my (former) students for their diligent work, especially Serra Koz and Müge Sarıgöl for their image contributions.

\section{Disclosure statement}

No potential conflict of interest was reported by the author(s).

\section{Notes on contributor}

Burçak Altay is assistant professor of practice at Bilkent University, Ankara, Turkey. She received her BArch from Middle East Technical University, MFA and PhD from Bilkent University. She previously worked as a programmer, designer, and technical coordinator at Skidmore, Owings \& Merrill architectural firm in New York, USA. She has published several articles on design education and practice in peer reviewed journals. Her research areas include: Architectural ethics and professional practice, inclusive and multisensory design, empathic design, creativity, and integrating mindfulness practices in design education.

\section{References}

Altay, Burçak. 2014. "User-centered Design through Learner-centered Instruction." Teaching in Higher Education 18 (2): 138-155. doi:10.1080/13562517.2013.827646.

Altay, Burçak. 2017. "Multisensory Inclusive Design Education: A 3D Experience." The Design Journal 20 (6): 821-846. doi:10.1080/14606925.2017.1371949.

Boyatzis, Richard E. 1998. Transforming Qualitative Information: Thematic Analysis and Code Development. Thousand Oaks, CA: Sage.

Braun, Virginia, and Victoria Clarke. 2006. "Using Thematic Analysis in Psychology." Qualitative Research in Psychology 3 (2): 77-101. doi:10.1191/1478088706qp063oa.

Cranz, Galen. 1998. The Chair: Rethinking Body Culture and Design. NY: W.W. Norton.

Elsen, Catherine, and Ann Heylighen. 2014. "Representations of Sensory Experiences in the Early Phases of Architectural Design: There Is More than Meets the Eye." Journal of Design Research 12 (4): 234-259. doi:10.1504/JDR.2014.065846.

Franck, Karen A., and Bianca R. Lepori. 2007. Architecture Form the inside Out. West Sussex: Wiley.

Howes, David. 2006. "Cross-talk between the Senses." The Senses and Society 1 (3): 381-390. doi:10.2752/174589206778476225.

Imai, Heide. 2008. "Senses on the Move: Multisensory Encounters with Street Vendors in the Japanese Urban Alleyway Roji." The Senses and Society 3 (3): 329-339. doi:10.2752/174589308X331350.

Irving, Andrew. 2013. "Bridges." The Senses and Society 8 (3): 290-313. doi:10.2752/174589313X13 712175020514.

Khoury, B., B. Knauper, F. Pagnini, N. Trent, A. Chiesa, and K. Carrière. 2017. "Embodied Mindfulness." Mindfulness 8 (5): 1160-1171. doi:10.1007/s12671-017-0700-7.

Malnar, Joy Monice, and Frank Vodvarka. 2004. Sensory Design. Minneapolis: University of Minnesota Press.

Murray, Scott. 2007. "Material Experience: Peter Zumthor's Thermal Bath at Vals." The Senses and Society 2 (3): 363-369. doi:10.2752/174589307X233594.

Nanda, Upali. 2005. "Sensthetics: A Crossmodal Approach to the Perception and Conception of Our Environments." Unpublished PhD Dissertation Submitted to the Office of Graduate Studies of Texas A\&M University.

Nanda, Upali. 2017. "A Sensthetic Approach to Designing for Health." Journal of Interior Design 42 (2): 7-12. doi:10.1111/joid.12098. 
Nhat Hanh, Thich. 1987. The Miracle of Mindfulness. Boston, MA: Beacon.

Pallasmaa, Juhani. 2005. The Eyes of the Skin: Architecture and the Senses. West Sussex: Wiley.

Pallasmaa, Juhani. 2015. "Body, Mind and Imagination: The Mental Essence in Architecture." In Mind in Architecture: Neuroscience, Embodiment, and the Future of Design, edited by Juhani Pallasmaa and Sarah Robinson, 51-74. Cambridge, MA: MIT Press.

Pallasmaa, Juhani. 2019. "Design for Sensory Reality: From Visuality to Existential Experience." Architectural Design 89 (6): 22-27. doi:10.1002/ad.2496.

Pheasant, Stephen. 2000. Bodyspace: Anthropometry, Ergonomics and Design. London: Taylor and Francis.

Pink, Sarah. 2012. Situating Everyday Life: Practice and Places. London: Sage.

Sucitto, Ajahn. 2015. Meditation: An Outline. Amaravati Pub: Hertfordshire.

Temple, Stephen. 2006. "Architecture of the Immediate: Steven Holl's Addition to the Cranbrook Institute of Science." The Senses and Society 1 (2): 255-258. doi:10.2752/174589206778055466.

Thera, Nyanoponika. 1988. The Heart of Buddhist Meditation: A Handbook of Mental Training Based on the Buddha's Way of Mindfulness. York Beach: Samuel Weiser.

van der Linden, Valerie, Hua Dong, and Ann Heylighen. 2016. "From Accessibility to Experience: Opportunities for Inclusive Design in Architectural Practice." Nordic Journal of Architectural Research 2: 33-58.

Varela, Francisco J., Evan Thompson, and Eleanor Rosch. 1991. The Embodied Mind: Cognitive Science and Human Experience. Cambridge, MA: MIT Press.

Xue, Haian, and Pieter M. A. Desmet. 2019. "Researcher Introspection for Experience-Driven Design Research." Design Studies 63: 37-69. doi:10.1016/j.destud.2019.03.001.

Zumthor, Peter. 1998. Thinking Architecture. Baden, Boston: Lars Müller Publishers. 